\title{
Endoscopic Transnasal Odontoidectomy
}

\author{
Jeffrey J. Falco ${ }^{1} \quad$ C. Arturo Solares ${ }^{2}$ Camilo Reyes $^{1}$ \\ ${ }^{1}$ Department of Otolaryngology-Head and Neck Surgery, Augusta \\ Universtiy Medical Center, Augusta Georgia, United States \\ 2 Department of Otolaryngology-Head and Neck Surgery, Emory \\ University, Atlanta, Georgia, United States
}

Address for correspondence Camilo Reyes, MD, Department of Otolaryngology-Head and Neck Surgery, Augusta University Medical Center, 1120 15th Street, Augusta, GA 30912, United States (e-mail: creyesgelves@augusta.edu).
Objectives The video demonstrates the steps for an endoscopic transnasal approach for resection of the odontoid causing platybasia with basilar invasion.

Design The video reviews the clinical presentation, preoperative workup and imaging, patient positioning, technical nuances of the procedure, reconstruction, and clinical outcomes including postoperative imaging.

Setting The surgery was performed by a skull base team including otolaryngologists and neurological surgeons at a large regional tertiary care facility.

Participants A 59-year-old female with the Chiari I malformation with history of multiple revision cervical spinal surgeries presents with neck pain. Preoperative imaging showed a hypoplastic clivus and platybasia with basilar invasion.

Main Outcome Measures The main outcome measures consist of safely removing the odontoid with appropriate closure, reversal of the patient symptoms, and prevention of both operative complications and ventral compression of the brainstem.

Results The patient's neck pain improved. There were no intraoperative or postoperative complications besides anterior rightward nasal septal deviation causing unilateral nasal obstruction. A septoplasty was performed to correct the septal deviation 6 months after the initial procedure.

Conclusions The endoscopic transnasal approach to the resection of odontoid is a safe and effective treatment to address basilar invasion and ventral compression of the brainstem.

The link to the video can be found at: https://youtu.be/m_c3-Vn-180.

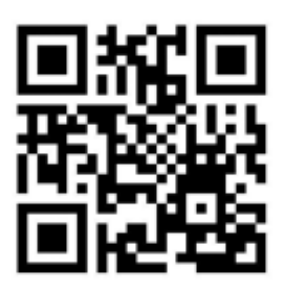

received

March 30, 2019 accepted after revision

January 4, 2020

published online

September 17, 2020

\section{Conflict of Interest \\ None declared.}

www.thieme.com/skullbasevideos

www.thieme.com/jnlsbvideos

DOI https://doi.org/ 10.1055/s-0040-1705161. ISSN 2193-6331.

\footnotetext{
(C) 2020. The Author(s).

This is an open access article published by Thieme under the terms of the Creative Commons Attribution-NonDerivative-NonCommercial-License, permitting copying and reproduction so long as the original work is given appropriate credit. Contents may not be used for commercial purposes, or adapted, remixed, transformed or built upon. (https://creativecommons.org/ licenses/by-nc-nd/4.0/) Georg Thieme Verlag KG, Rüdigerstraße 14, 70469 Stuttgart, Germany
} 


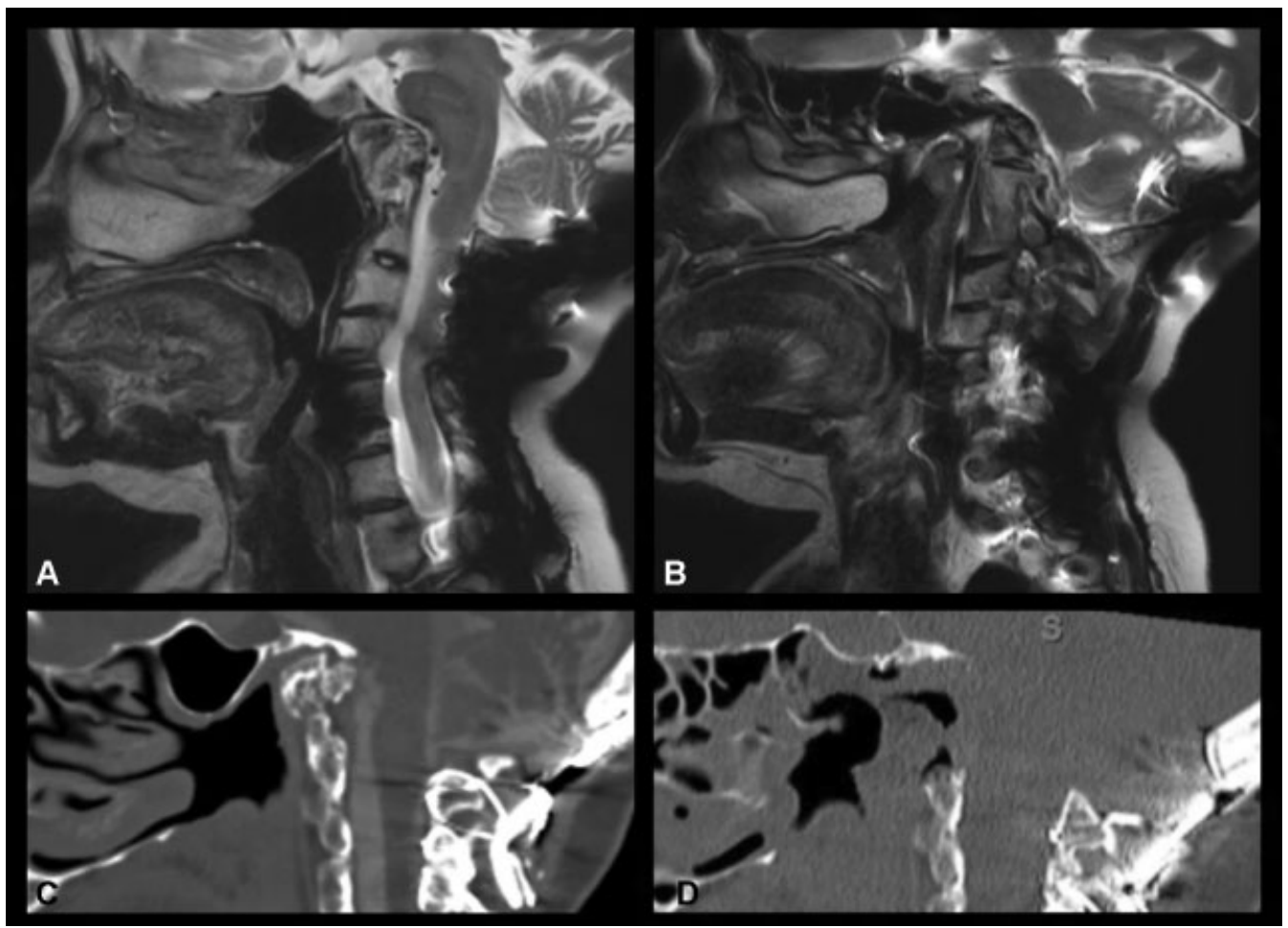

Fig. 1 (A, B). Sagittal preoperative magnetic resonance imaging showing multiple congenital malformations of the craniocervical junction including a hypoplastic clivus, platybasia with basilar invasion, and congenital fusion of C2-C3. C-D. Sagittal preoperative (C) and postoperative (D) computed tomography scans showing occipital cervical fusion and superimposed platybasia with basilar invagination. Postoperative scan (D) showing resection of odontoid without significant edema or hematoma.

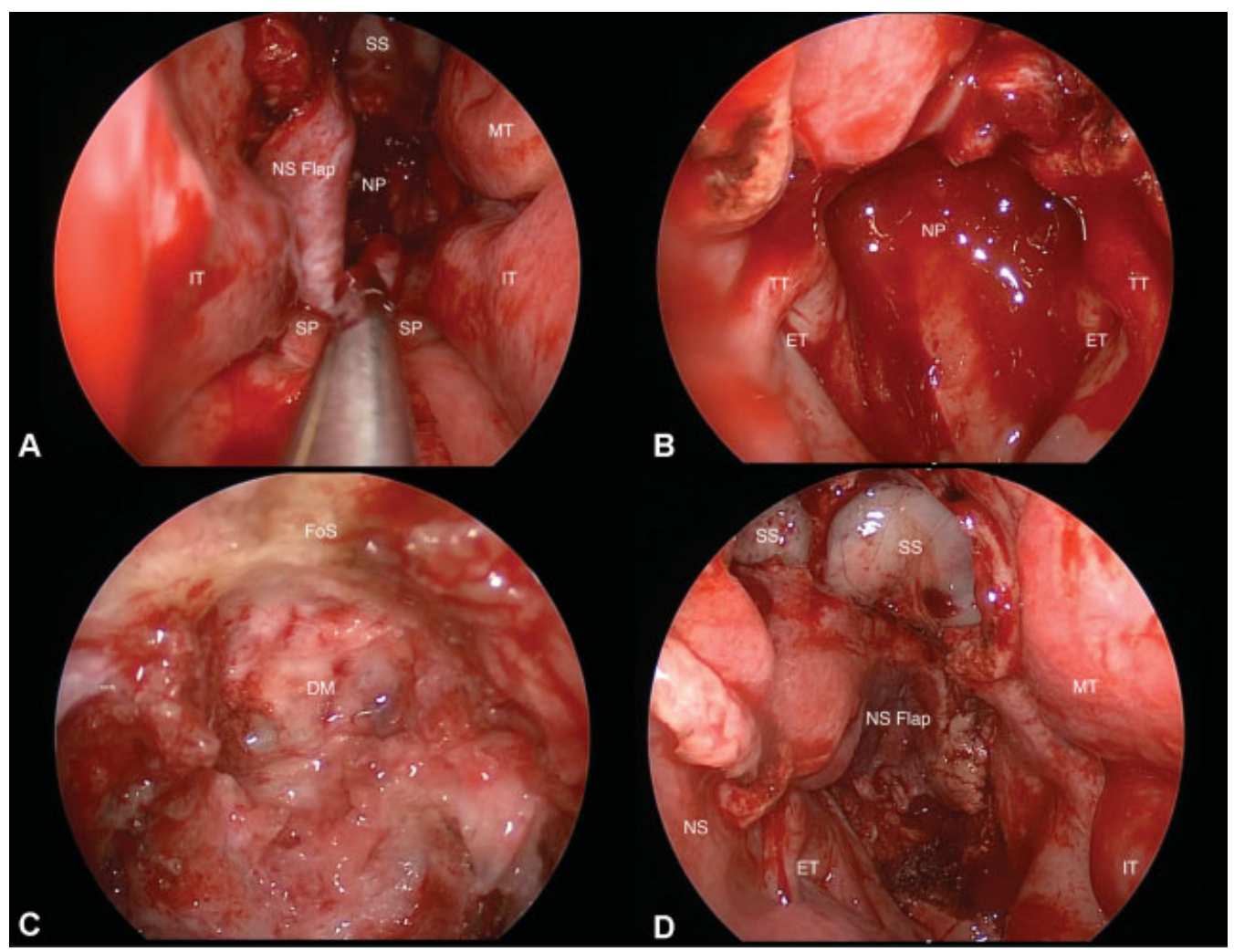

Fig. 2 (A) Exposure of nasopharynx using nasal septal flap. (B) Nasopharynx., (C) Resection of odontoid.. (D) Reconstruction using nasal septal flap, Surgicel (Ethicon), Gelfoam Powder (Pfizer) with Thrombin (King), and nasal trumpet., DM, dura mater; ET, Eustachian tube; IT, inferior turbinate; MT, middle turbinate; NP, nasopharynx; NS, nasal septal; SS, sphenoid sinus. 